\title{
Parametric Studies of Laminated Cooling Configurations: Overall Cooling Effectiveness
}

\author{
Chen Wang ${ }^{D}$, Chunhua Wang, and Jingzhou Zhang \\ School of Energy and Power Engineering, Nanjing University of Aeronautics and Astronautics, Nanjing 210016, China \\ Correspondence should be addressed to Chen Wang; wangchen4520@163.com
}

Received 4 November 2020; Revised 15 January 2021; Accepted 20 January 2021; Published 11 February 2021

Academic Editor: Angelo Cervone

Copyright ( 2021 Chen Wang et al. This is an open access article distributed under the Creative Commons Attribution License, which permits unrestricted use, distribution, and reproduction in any medium, provided the original work is properly cited.

\begin{abstract}
Combing the advantages of film cooling, impingement cooling, and enhanced cooling by pin fins, laminated cooling is attracting more and more attention. This study investigates the effects of geometric and thermodynamic parameters on overall cooling effectiveness of laminated configuration, and model experiments were carried out to validate the numerical results. It is found that the increases in film cooling hole diameter and pin fin diameter both result in the increase in cooling effectiveness, but the increases in impingement hole diameter, impingement height, and spanwise hole pitch degrade the cooling performance. The increase of the coolant flow rate causes the increase in cooling efficiency, but this effect becomes weaker at a high coolant flow rate. The coolant-to-mainstream density ratio has no obvious effect on cooling effectiveness but affects wall temperature obviously. Moreover, based on the numerical results, an empirical correlation is developed to predict the overall cooling efficiency in a specific range, and a genetic algorithm is applied to determine the empirical parameters. Compared with the numerical results, the mean prediction error (relative value) of the correlation can reach $8.3 \%$.
\end{abstract}

\section{Introduction}

Among the cooling methods of the gas turbine, film cooling is the most common and effective cooling method and has been widely researched. The results $[1,2]$ show that the improvement of film cooling effectiveness is mainly to restrain the development of the kidney vortex and reduce the normal penetration ability of cooling jet to the mainstream. In the novel film cooling schemes, researchers have designed combined-hole [3, 4], antivortex hole [5, 6], trench $[7,8]$, and ridge-shaped tabs $[9,10]$ to suppress the strength of the kidney vortex. However, with the development trend of gas turbines, the combustor outlet temperature continues to increase for higher recycling efficiency, and the single cooling method cannot fulfill the requirements. In order to reduce the thermal stress and extend the service life of hot components, double-wall composite cooling configurations including a jet issuing wall and a target wall spaced from the jet issuing wall have been developed. After impinging on the inner surface of the target plate, the coolant is extracted from the internal channel and discharged from the film cooling holes. Because combining the advantages of film cooling and jet impingement cooling, double-wall cooling has been widely studied and applied in the past years. Factors like the jet Reynolds number, internal channel height, hole diameter, and hole number as well as hole spacing have also been examined in detail [11-15].

For further improvement of cooling performance, laminated cooling is developed by adopting pin fins in the internal channel of double-wall cooling configuration. As shown in Figure 1, laminated cooling is usually achieved in a compact space constructed by an impingement layer, a film layer, and arrays of pin fins in between. The coolant enters the internal channel from the impingement holes, then impinges on the inner surface of the target plate and interacts with pin fins, and is finally discharged from the film cooling holes. The pin fins connect the film layer and impingement layer directly and thus enhance the heat conduction in the solid domain. Furthermore, the application of pin fins promotes the convective heat transfer in the internal channel and 


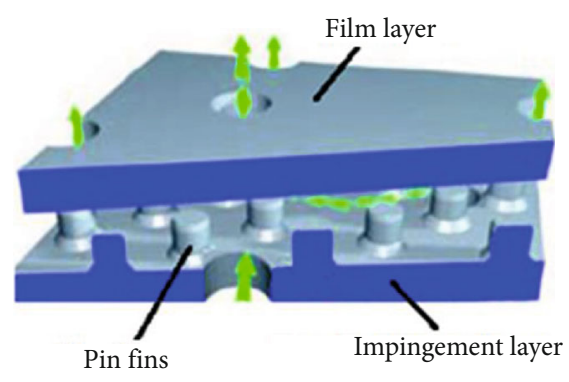

(a)

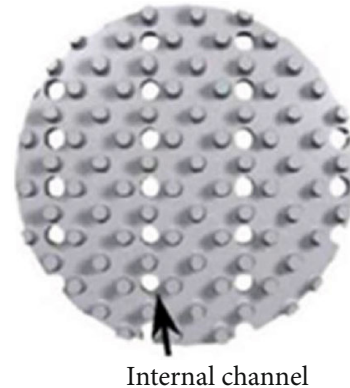

(b)

Figure 1: Schematic of laminated cooling [16].

increases the contact area between the coolant and solid [16]. Rolls-Royce plc has firstly applied the laminated cooling into the thermal protection of the TRANSPLY combustion liner, and the experimental results show that this new composite cooling structure can achieve the same cooling performance with only $67 \%$ coolant consumption compared with traditional cases [17]. The laminated cooling has also been used in many other combustors, and the running data show that the cooling efficiency can reach $0.7 \sim 0.9$ [18]. The experimental results from Kim et al. [19] also show that, compared with film cooling with the same thickness, the cooling effectiveness increases about $47 \% \sim 141 \%$ by applying laminated cooling.

Due to its superior cooling performance, laminated cooling has attracted more and more attention from academia and industry. Funazaki and Hachiya $[20,21]$ compared the heat transfer between laminated and traditional double-wall cooling configurations. Their results show that the heat flux on the target surface increases about $50 \%$ by introducing pin fins. Moreover, pressure drop and Nusselt number on pin fin surfaces decrease with the increase of the pin fin height. Nakamata et al. [22, 23] studied the effects of pin fin arrangement and sizes on the heat transfer. They reported that the application of pin fins improves cooling effectiveness remarkably in the upstream region but has no obvious effect in the downstream region. Luo et al. [24] studied the dimple effects on the heat transfer and friction performance of laminated configuration. Their results show that, as the dimple diameter and depth increases, heat transfer on the target surface increases firstly because of the increase of flow reattachment and recirculation and then decreases due to the flow separation. Luo et al. [25] also indicated that adding pin fin normalized location and diameter degrades the heat transfer on the target surface but reduces the friction factor. The experimental results from Wang et al. [26] show that the angle impact of the film cooling hole on heat transfer is very pronounced. Even without the pin fin, high cooling efficiency can be achieved by adjusting the angle of the film cooling hole. Pu et al. [27] performed experimental studies to compare the laminated cooling and film cooling endwall. They indicated that adding turbulence intensity results in the decrease of overall cooling effectiveness, especially for laminated cases. Furthermore, the diamond-shaped pin fins and large-size impingement holes can improve cooling perfor- mance. The experimental results from Rao et al. [28] showed that the introduction of effusion holes and pin fins can inhibit the strength of the cross flow and enhance the uniform heat transfer. Moreover, in the most cases, the laminated configuration generates better cooling performance on the endwall than that on the flat plate. Sweeney and Rhodes [29] developed snow-shaped pin fins in a laminated configuration. They indicated that, at small hole spacing, the inclination of film cooling hole can improve cooling effectiveness effectively, but this impact becomes weaker as the hole spacing increases. Tan et al. [30] compared the elliptical, dropshaped, and circular pin fins and found that the shaped pin fins generate better cooling performance. Wang et al. [31] studied the thermal stress characteristics of laminated configurations. They indicated that the spanwise hole-to-hole pitch has the most obvious effect, while the influence of impinging hole diameter and pin fin diameter is very weak. The influence of pitch-to-diameter ratios of impingement and film cooling holes was studied by Zhou et al. [32]. They indicated that the increase of pitch-to-diameter ratio of impingement holes results in the exponential increase of pressure loss.

Due to the numerous structural parameters of laminated configuration, its influence is still a main emphasis worthy of attention. Moreover, the combustion chamber has a hightemperature and high-pressure environment, which is significantly different from the operating conditions in the experiment. Therefore, it is necessary to simulate the cooling performance of laminated configurations under real conditions by numerical methods. In this paper, the cooling performances of laminated configurations were studied, and the effects of thermodynamic and geometric parameters on overall cooling effectiveness were analyzed in detail. The validation experiments were carried out to test the numerical results. Moreover, an empirical correlation for predicting overall cooling efficiency was developed, and the genetic algorithm is applied to determine the empirical parameters.

\section{Computational Domain and Inlet Conditions}

As shown in Figure 2(a), the computational domain consists of a mainstream channel, a coolant channel, and a laminated cooling structure. The detailed arrangements of holes and pin fins in the cooling structure are shown in Figure 2(b). $P$ denotes the hole pitch on the spanwise direction, and $S$ 


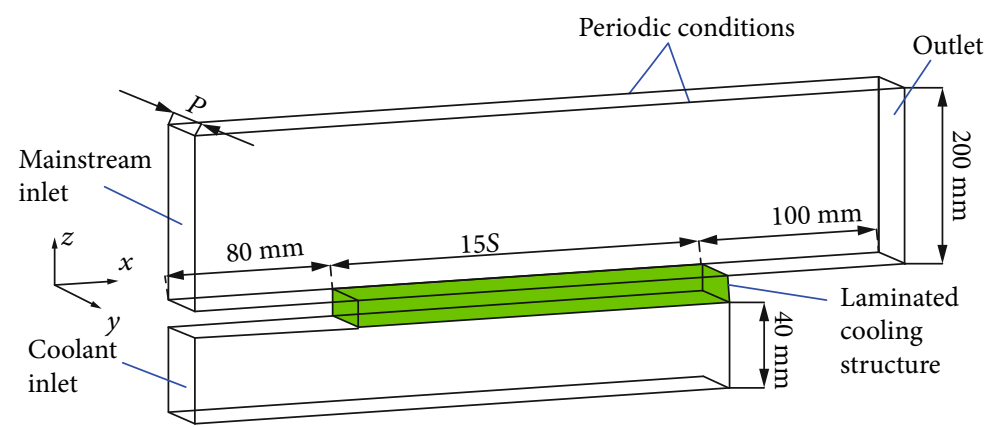

(a) Computational domain
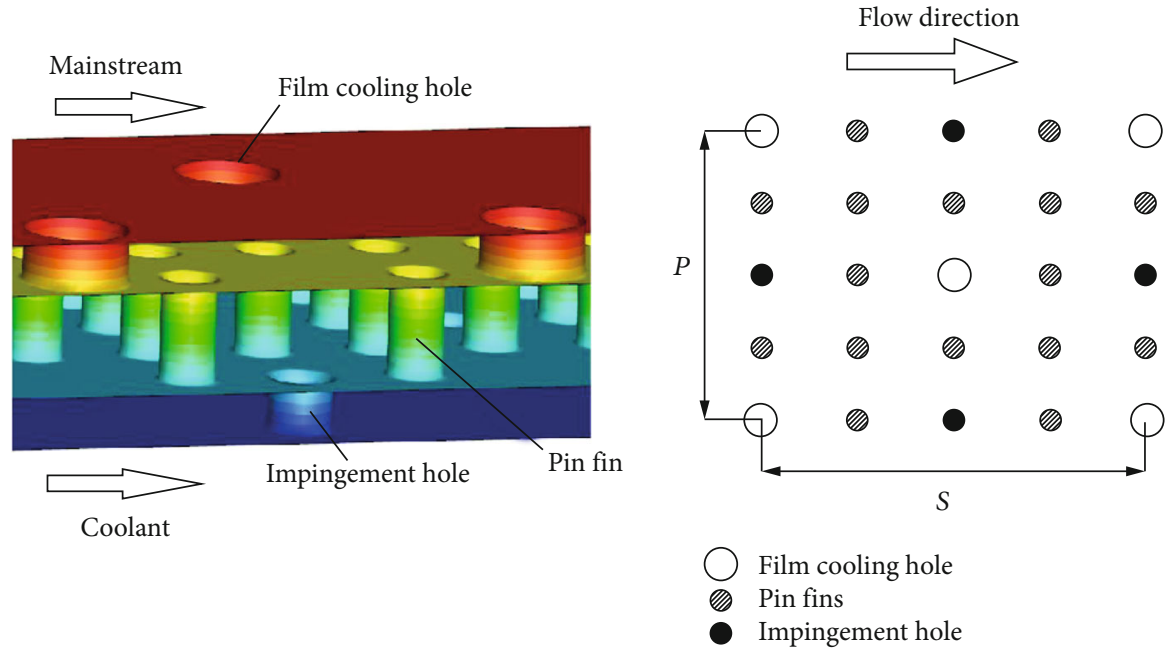

(b) Arrangement of holes and pin fins

Figure 2: Geometry of computational domain.

TABLE 1: Changing interval of geometric parameters in the present cases.

\begin{tabular}{lcc}
\hline Variable & Unit & Changing interval \\
\hline$d_{\mathrm{i}} / d_{\mathrm{f}}$ & - & $0.5 \sim 1$ \\
$H / d_{\mathrm{i}}$ & - & $0.5 \sim 3$ \\
$S / d_{\mathrm{i}}$ & - & $6 \sim 12$ \\
$P / S$ & - & $1 \sim 2$ \\
$\varepsilon$ & - & $0.35 \sim 0.65$ \\
\hline
\end{tabular}

denotes the hole spacing on the streamwise direction. Thickness of the film plate and impingement plate is both $0.5 \mathrm{~mm}$, and the variations of other geometric parameters of laminated structure are listed in Table $1 . d_{\mathrm{i}}, d_{\mathrm{f}}, H$, and $\varepsilon$ the denote impingement hole diameter, film cooling hole diameter, impingement height, and blocking rate, respectively. The design parameters are to apply the laminate configurations to a combustor liner; the selection range of parameters is expanded on the basis of the actual structure. The mainstream channel has a length of $15 S+180 \mathrm{~mm}$, a width of $P$, and a height of $200 \mathrm{~mm}$. The coolant channel has a length of $15 S+80 \mathrm{~mm}$, a width of $P$, and a height of $40 \mathrm{~mm}$. The origin of the axis is located in the center of first-row film cooling hole. The $x, y$, and $z$ axes denote the streamwise, spanwise, and vertical directions to the cooling surface, respectively.

The mainstream has an inlet velocity of $20 \mathrm{~m} / \mathrm{s}$, temperature of $2000 \mathrm{~K}$, and pressure of $3.0 \mathrm{MPa}$. Mass flow inlet boundary condition is specified on the coolant inlet. The coolant consumption rate per unit area $\left(G_{\mathrm{c}}\right)$ changes from $3 \mathrm{~kg} / \mathrm{m}^{2}$ s to $27 \mathrm{~kg} / \mathrm{m}^{2} \mathrm{~s}$. The coolant temperature changes from $680 \mathrm{~K} \sim 1000 \mathrm{~K}$. The solid phase has a density of $8934 \mathrm{~kg} / \mathrm{m}^{3}$, a specific heat of $550 \mathrm{~J} /(\mathrm{kg} \cdot \mathrm{K})$, and a thermal conductivity of $25 \mathrm{~W} /(\mathrm{m} \cdot \mathrm{K})$. Ideal gas is used for the gas phase, and the change of viscosity follows Sutherland's law [33].

Structured meshes shown in Figure 3 are generated by Gambit software [34]. Near the wall surface, the grid points are refined to ensure that $\mathrm{z}^{+} \approx 1.0$. To test the accuracy of turbulence models, CFD results with different turbulence models are compared with the experimental data from Nakamata et al. [22]. In the computational domain, the film cooling hole has a diameter of $4 \mathrm{~mm}$ and a height of $3 \mathrm{~mm}$. The impingement hole has a diameter of $4 \mathrm{~mm}$ and a height of $4 \mathrm{~mm}$. The pin fin has a diameter of $3 \mathrm{~mm}$ and a height of $6 \mathrm{~mm}$. The hole pitch is $20 \mathrm{~mm}$, and the hole spacing is $10 \mathrm{~mm}$. The mainstream and coolant temperatures are $673 \mathrm{~K}$ and $336.5 \mathrm{~K}$. As shown in Figure 4, the predication accuracy of the realizable $k-\varepsilon$ model is higher than that of 


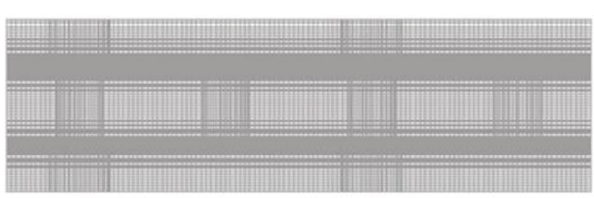

(a) Central plane $(y=0)$

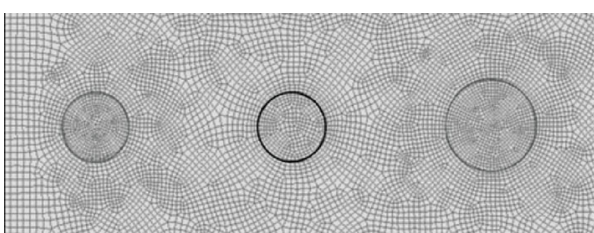

(b) Surface of film plate

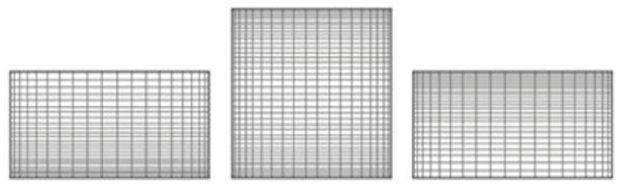

(c) Surfaces of hole and pin fin

Figure 3: Grids used in the present study.

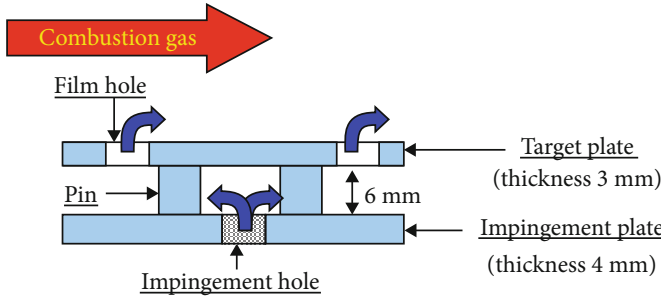

(a) Laminated cooling model from Nakamata et al. [22]

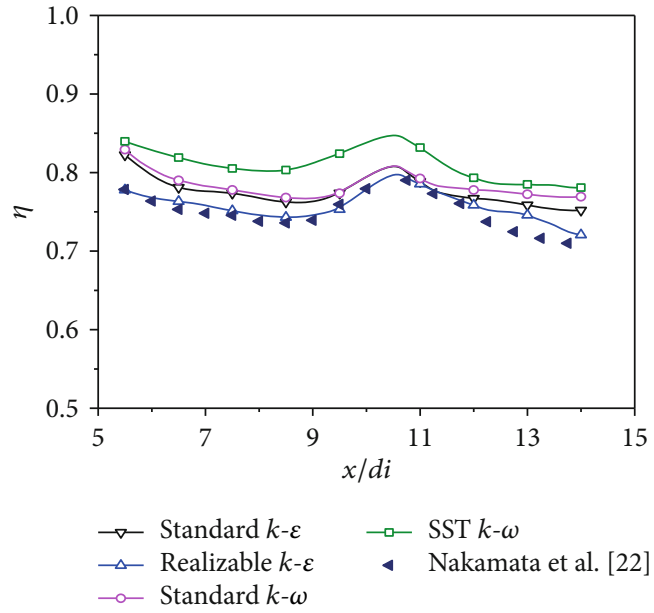

(b) Comparison of turbulence models

Figure 4: Test of turbulence models.

other models. So, in the present study, realizable $k-\varepsilon$ is used to for turbulence modeling, and enhanced wall function is applied for wall treatment. Grid number is determined by grid independent tests. In the present cases, the grid number is between 9 million and 18 million.

Ansys Fluent software [33] is used for solving the governing equations. The second-order scheme and least square cell-based scheme are applied for discretizing the pressure and gradient term, respectively. The second-order upwind scheme is applied for the solution of energy and momentum equations. The pressure-velocity coupling is done by the SIMPLE algorithm. Three criteria are used to determine whether the calculation is convergent: (1) value of normalized residuals $\left(\approx 10^{-6}\right)$, $(2)$ variation of local effectiveness $\left(\approx 10^{-2}\right)$, and $(3)$ mass balance error $\left(\approx 10^{-6}\right)$.

\section{Model Validation}

The experiments were carried out for model validation. The experimental system is shown in Figure 5. Supplied by a compressed air supply $(0.8 \mathrm{MPa})$, the primary flow passes through a calibrated orifice flow meter and then enters the combustor. The combustor is used to generate high temperature flue gas. The flue gas is routed through a section with baffles to ensure obtaining a uniform temperature distribution across the cross-section and then enters the test sections. The mainstream temperature and velocity is $600 \mathrm{~K}$ and $20 \mathrm{~m} / \mathrm{s}$ in the present study. The coolant temperature is $300 \mathrm{~K}$, and the velocity is calculated by the blowing ratio ( $M$ is the blowing ratio, defined as $M=\left(\rho_{c} u_{c}\right) /\left(\rho_{\infty} u_{\infty}\right)$, where $\rho_{c}$ and $\rho_{\infty}$ are the mainstream-flow density and the coolant-flow density, respectively).

The inlet surface of the test section has a width of $120 \mathrm{~mm}$ and a height of $200 \mathrm{~mm}$. The infrared thermography is used to measure the temperature of the hot-side surface through the infrared glass on the top surface of test sections. This infrared glass has a high nominal transmissivity of nearly 0.97 in the long IR band $(8 \sim 14 \mathrm{~mm})$ of the infrared spectrum. The infrared thermography (Mag32HF model) is produced by Magnity Electronics Co. Ltd., and its testing range and accuracy are $-20 \sim 500^{\circ} \mathrm{C}$ and $\pm 1^{\circ} \mathrm{C}$, respectively. The infrared measurement calibration was conducted in advance by using five thermocouples embedded on the black-painted test surface. The detailed measurement and calibration steps are 


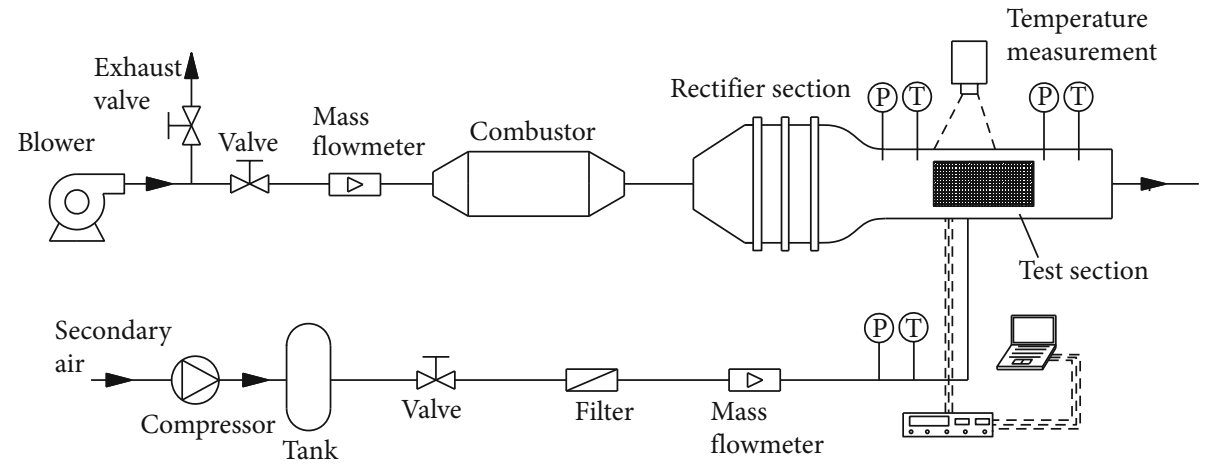

(a) Experimental system
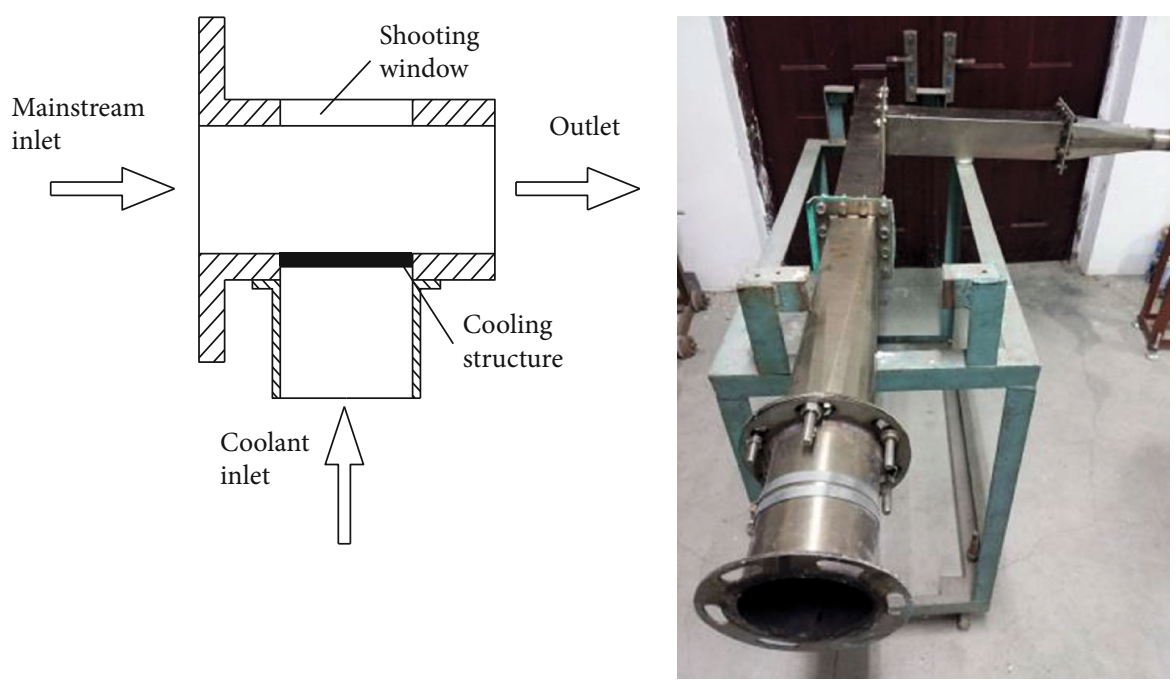

(b) Test section

(c) Physical structure used in the experiment

FIGURE 5: Experimental system in the present study.

illustrated by Ji [35]. The laminated cooling structures shown in Figure 6 are made of 316 stainless steel. In the present studies, two laminated structures with the cooling area of $100 \mathrm{~mm} \times 100 \mathrm{~mm}$ are tested, and their geometric parameters are listed in Table 2.

Figure 7 shows the distribution of cooling effectiveness on the test surfaces. Cooling efficiency increases with the blowing ratio, especially at low coolant consumption. Case 1 generates much better cooling performance than Case 2 . However, due to the large opening rate of the film cooling hole, the coolant consumption for Case 1 is also higher than that for Case 2 at the same blowing ratio. Figure 8 compares the spanwise averaged overall cooling effectiveness by numerical simulation and experimental measurement. In the start zone, the calculation error is higher than that in the stable zone, especially for Case 2. It can be contributed to by two factors: (1) the machining error may cause the difference; (2) the superposition process of the gas film in the start zone is very complicated to be predicted. However, the error level is not high. The maximum relative errors for Case 1 and Case 2 are $10.3 \%$ and 14.5\%, respectively. In addition, Figure 9 compares the centerline averaged overall cooling effectiveness; the maximum relative errors for Case 1 and
Case 2 are $3.4 \%$ and $2.8 \%$, respectively. Overall, CFD results agree with the experimental results well.

\section{Results Analysis}

4.1. Effects of Thermodynamic Parameters. Figure 10 shows the influences of the coolant flow rate on the hot-side wall temperature distribution. The laminated configuration has a size of $\left(d_{\mathrm{i}}, d_{\mathrm{f}}, d_{2}, H, S, P\right)=(0.9,1.5,0.8,1.0,6.8,6.8) \mathrm{mm}$. The density ratio is 2.5 . With the increase of the streamwise distance, temperature decreases sharply due to the superposition effect of the gas film. In the front region, the coolant jets injected from the front rows of film cooling holes experience a developing stage to merge together; the local overall cooling effectiveness is certainly small. In the middle and trailing regions, due to the superposition effect of upstream coolant jets, a well-covered film layer (namely, fully developed stage) begins to form, so that the local effectiveness reaches its maximum value gradually. However, in the trailing-edge region, the temperature becomes stable and does not change with streamwise distance obviously. Overall, increasing the coolant flow rate reduces wall temperature effectively. Figure 11 shows the variations of laterally averaged cooling 


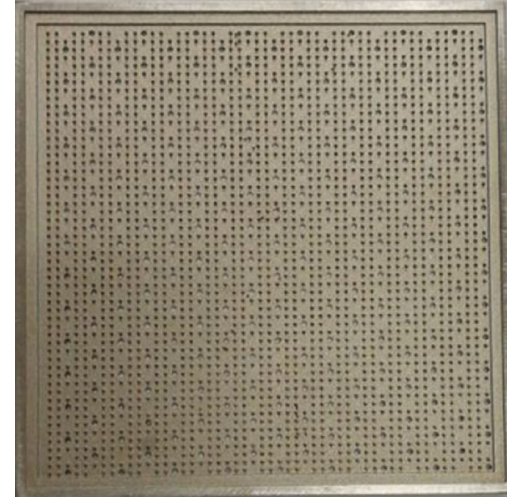

(a) Pin fins inside the cavity

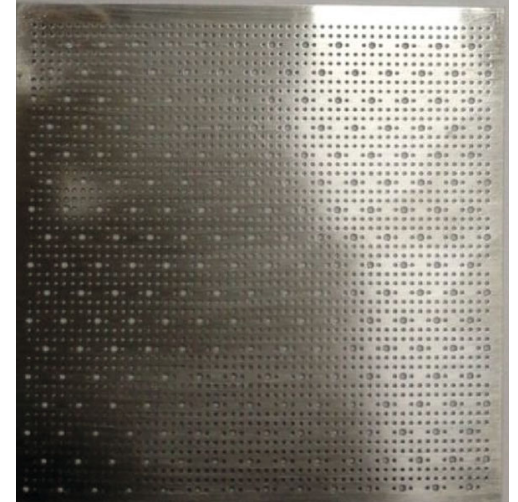

(b) Cool-side wall of impingement plate

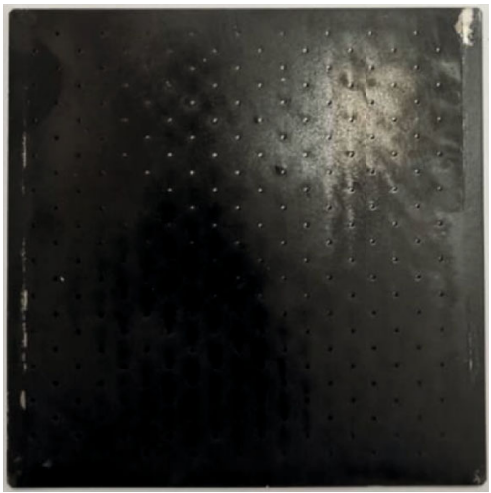

(c) Hot-side wall of film cooling plate (with black paint)

Figure 6: Test pieces of laminated cooling.

TABLE 2: Detailed geometric parameters for test pieces.

\begin{tabular}{lccccc}
\hline No. & $d_{\mathrm{i}} / d_{\mathrm{f}}$ & $H / d_{\mathrm{i}}$ & $S / d_{\mathrm{i}}$ & $P / S$ & $\varepsilon$ \\
\hline Case 1 & 0.5 & 2 & 12 & 1 & 0.33 \\
Case 2 & 1 & 1 & 12 & 2 & 0.48 \\
\hline
\end{tabular}

effectiveness with streamwise distance at different coolant flow rates. At the low flow rate, increasing the coolant flow rate results in the increase of cooling efficiency obviously. For example, the area-averaged cooling efficiency increases from 0.763 to 0.908 by increasing the coolant flow rate from 3 to $18 \mathrm{~kg} / \mathrm{m}^{2} \mathrm{~s}$. However, at a high coolant flow rate, cooling efficiency becomes stable. For example, the area-averaged cooling efficiency only changes about $0.83 \%$ as the cooling flow rate increases from 18 to $24 \mathrm{~kg} / \mathrm{m}^{2} \mathrm{~s}$, which is due to a well-covered film layer on the hot-side surface of the laminated configuration, and the cooling efficiency is very high; it does not change obviously with the coolant flow rate.

Figure 12 shows the influences of coolant-to-mainstream density ratio on the film-plate temperature distribution. The coolant consumption per unit area is $8 \mathrm{~kg} / \mathrm{m}^{2}$ s. Increasing the density ratio results in the decrease of the wall temperature obviously. For example, the area-averaged temperature of the outer surface decreases from 1087 to $783 \mathrm{~K}$ as the density ratio increases from 2.0 to 3.0. Figure 13 shows the variations of laterally averaged cooling effectiveness with the stream- wise distance at different density ratios. The effect of the density ratio on film cooling effectiveness is very weak. For example, at $x / S=8.0$, the cooling efficiency only changes from 0.892 to 0.894 by increasing the density ratio from 2.0 to 3.0. So, in the present cases, the increase of the density ratio can reduce the wall temperature but has no obvious impact on cooling efficiency.

4.2. Effects of Geometric Parameters. Figure 14 shows the influences of the film hole diameter on streamline distribution on the central plane $(y=0)$. In the present cases, $\left(d_{\mathrm{i}}, d_{2}, H, S, P\right)=(0.9,0.8,1.0,6.8,6.8) \mathrm{mm}, \quad G_{\mathrm{c}}=8 \mathrm{~kg} / \mathrm{m}^{2} \mathrm{~s}$, and $\mathrm{DR}=2.5$. Increasing the hole size can reduce the jet penetration into the mainstream. It is because the increase of the hole size causes the increase of the opening rate and the decrease of the jet momentum. Figure 15 shows the variation of laterally averaged cooling efficiency with streamwise distance at different film hole diameters. At $x / S=0$, the increase of the hole size from 0.9 to $1.5 \mathrm{~mm}$ causes the increase of cooling efficiency from 0.655 to 0.703 . At $x / S=15$, the increase of the hole size causes the increase of cooling efficiency from 0.893 to 0.931 . Overall, increasing the film hole diameter improves coolant coverage and cooling performance effectively.

Figures 16(a) and 16(b) show the streamline distribution on the central plane at different impingement heights. In the present cases, $\left(d_{\mathrm{i}}, d_{\mathrm{f}}, d_{2}, S, P\right)=(0.9,1.5,0.8,6.8,6.8) \mathrm{mm}$, $G_{\mathrm{c}}=8 \mathrm{~kg} / \mathrm{m}^{2} \mathrm{~s}$, and $\mathrm{DR}=2.5$. On both sides of the 

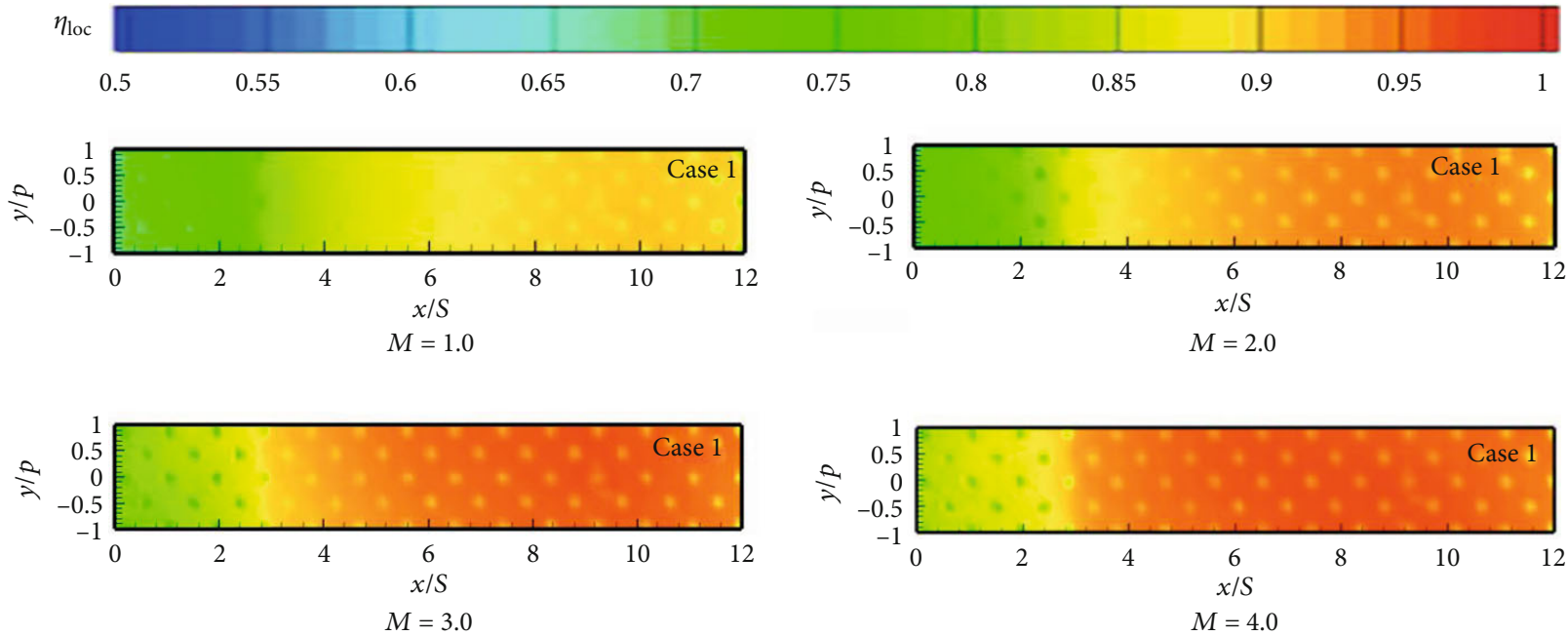

(a) Case 1
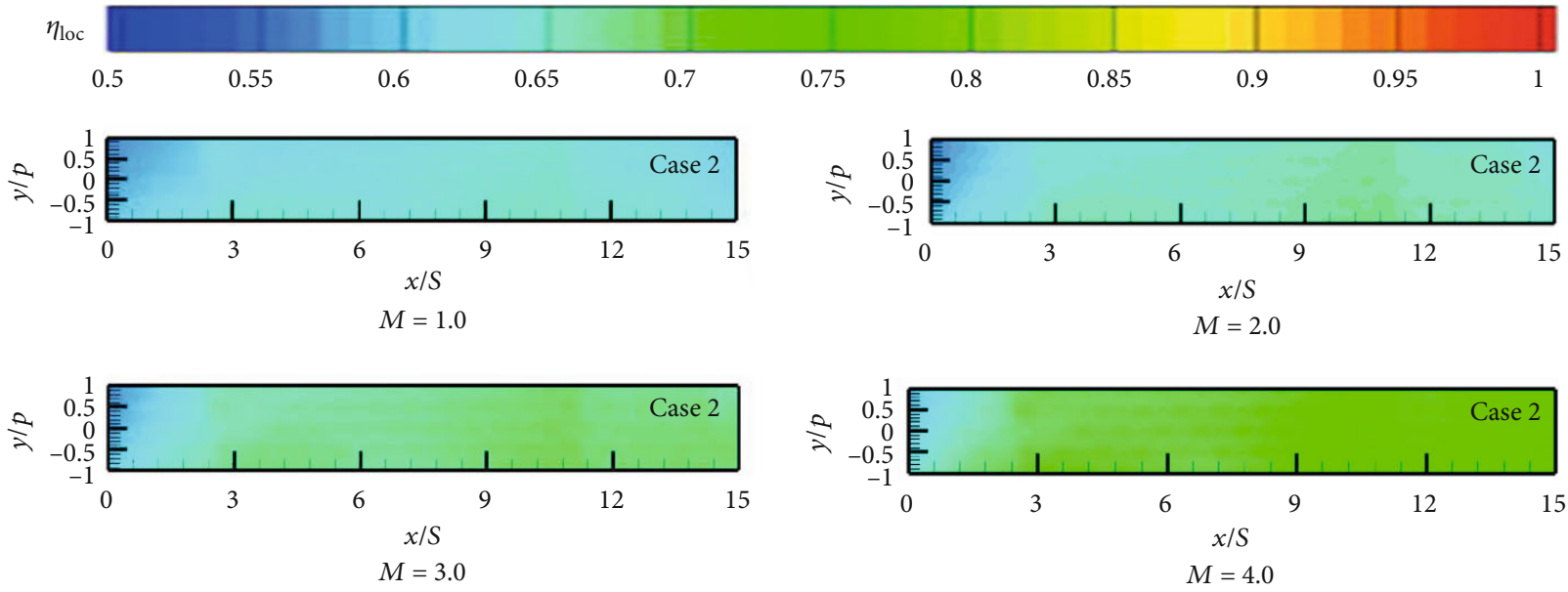

(b) Case 2

Figure 7: Distribution of cooling effectiveness on the hot-side surface of the laminated configuration.
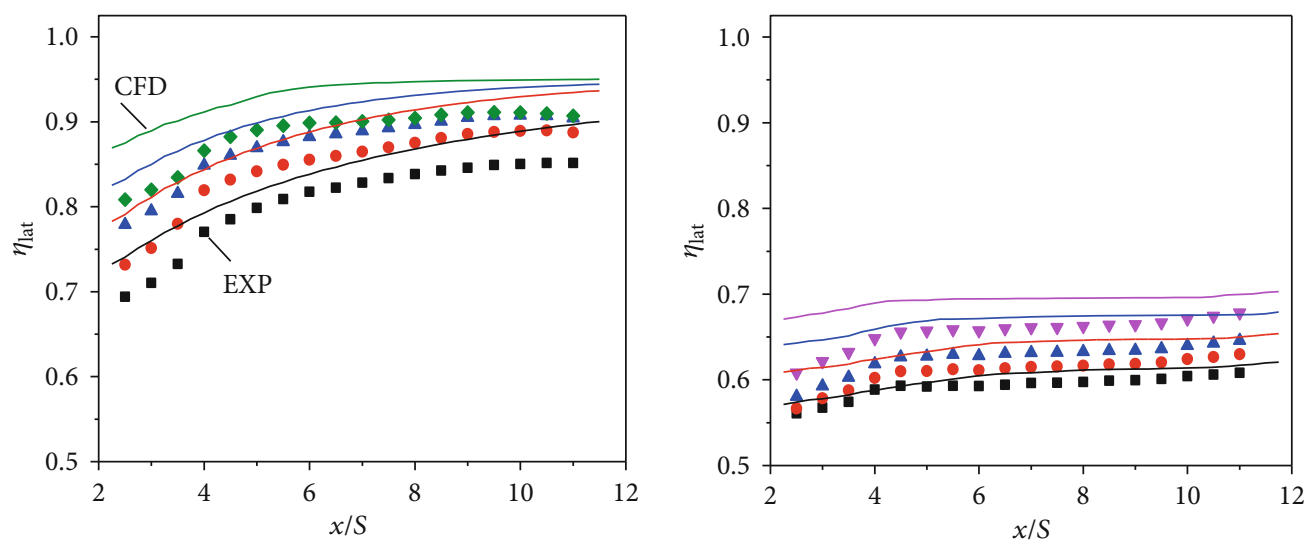

$\begin{array}{ll}\text { - } M=1 & \Delta M=3 \\ \text { - } M=2 & \diamond M=4\end{array}$

(a) Case 1

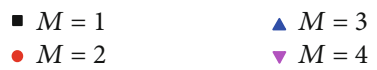

(b) Case 2

Figure 8: Comparison of the spanwise averaged overall cooling effectiveness. 


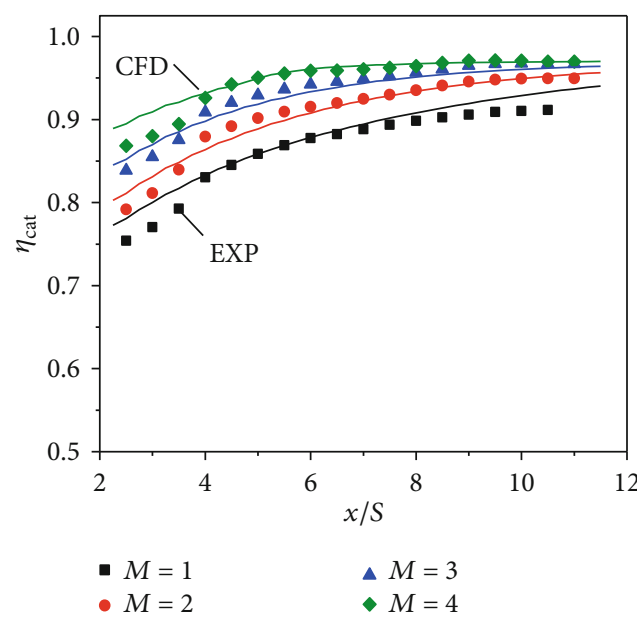

(a) Case 1

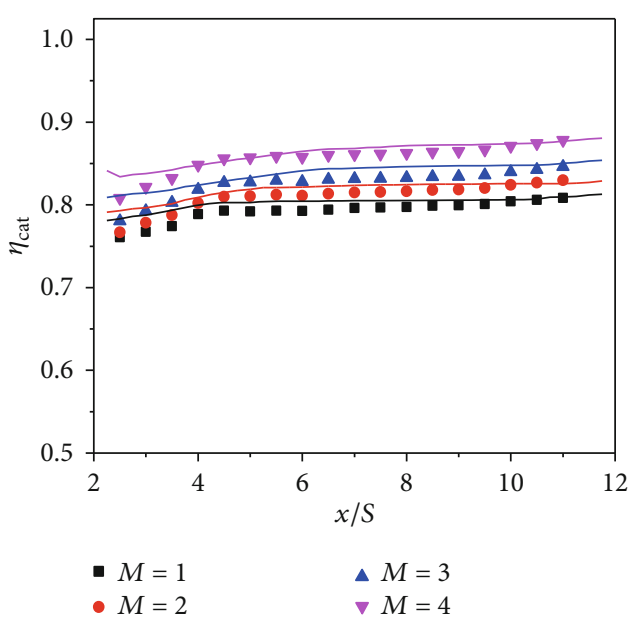

(b) Case 2

FIGURE 9: Comparison of the centerline averaged overall cooling effectiveness.
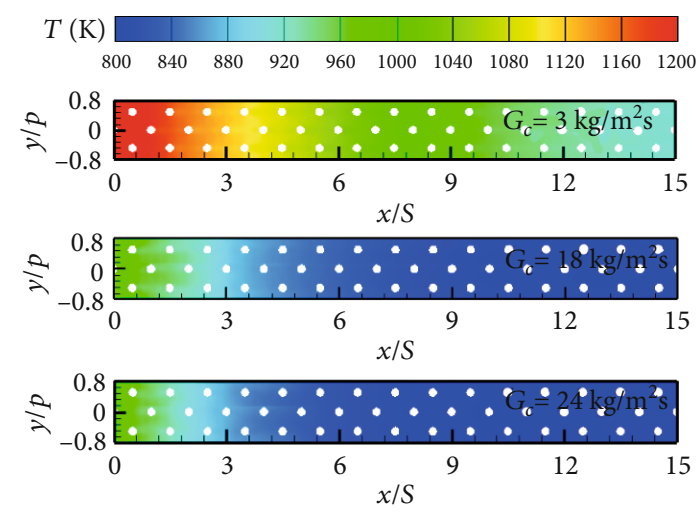

Figure 10: Temperature distribution on the hot-side surface at different coolant flow rates.

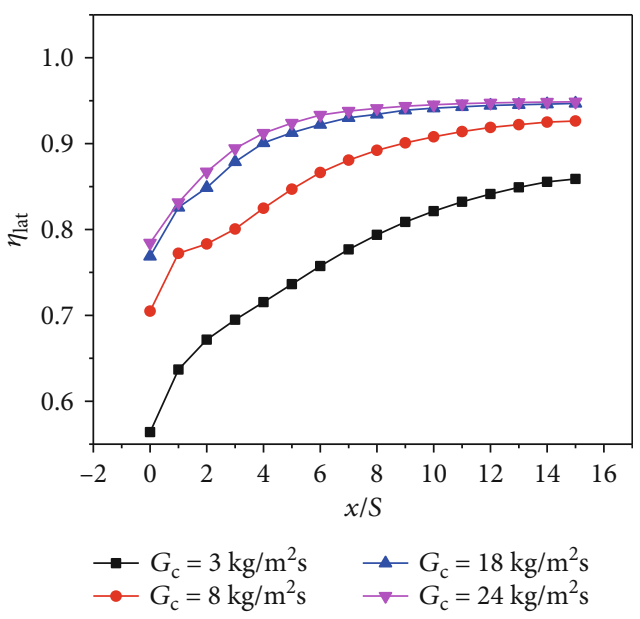

Figure 11: Influence of coolant flow rate on cooling efficiency distribution. impingement jet, a pair of roller vortices is generated. It can be found that increasing the impingement height results in the increase of the roller vortex scale. Moreover, the centers of roller vortices move upwards as the impingement height increases. Figure 17 shows the variation of the cooling efficiency with the streamwise distance at different impingement heights. As the impingement height increases, the momentum loss caused by the mixture between the jet and surrounding gas increases, which degrades the impingement cooling capability. On the other hand, increasing the impingement height also leads to the increase of the surface area of pin fins, which enhances the convective heat transfer between the coolant and pins. In the present cases, the first effect takes the dominant role, and the cooling effectiveness decreases with the increase of the impingement height. However, the impact of the impingement height on cooling effectiveness is not very obvious. For example, as the impingement height decreases from $3 \mathrm{~mm}$ to $1 \mathrm{~mm}$, the area-averaged cooling effectiveness only decreases by about $2.5 \%$.

Figures 16(a) and 16(c) show the influences of the impingement hole diameter on streamline distribution on the central plane. In the present cases, $\left(d_{\mathrm{f}}, d_{2}, H, S, P\right)=$ $(0.9,1.5,0.8,1.0,6.8,6.8) \mathrm{mm}, G_{c}=8 \mathrm{~kg} / \mathrm{m}^{2} \mathrm{~s}$, and $\mathrm{DR}=$ 2.5. As the coolant enters the impingement hole, the streamline deflects, and the stagnation point on the target surface moves downstream. As the hole size increases, the streamline deflection becomes more and more pronounced; accordingly, the impingement cooling performance becomes worse. Furthermore, the increase of the hole size causes the decrease of the jet velocity, which also deteriorates cooling performance. For example, the temperature on the target surface increases from 854 to $903 \mathrm{~K}$ by increasing the impingement hole diameter from 0.9 to $1.5 \mathrm{~mm}$. Figure 18 shows influences of impingement height on cooling efficiency distribution. As the streamwise distance increases, the cooling efficiency decreases firstly and then keeps stable. Compared with the film hole, the effect of the impingement hole size on cooling 


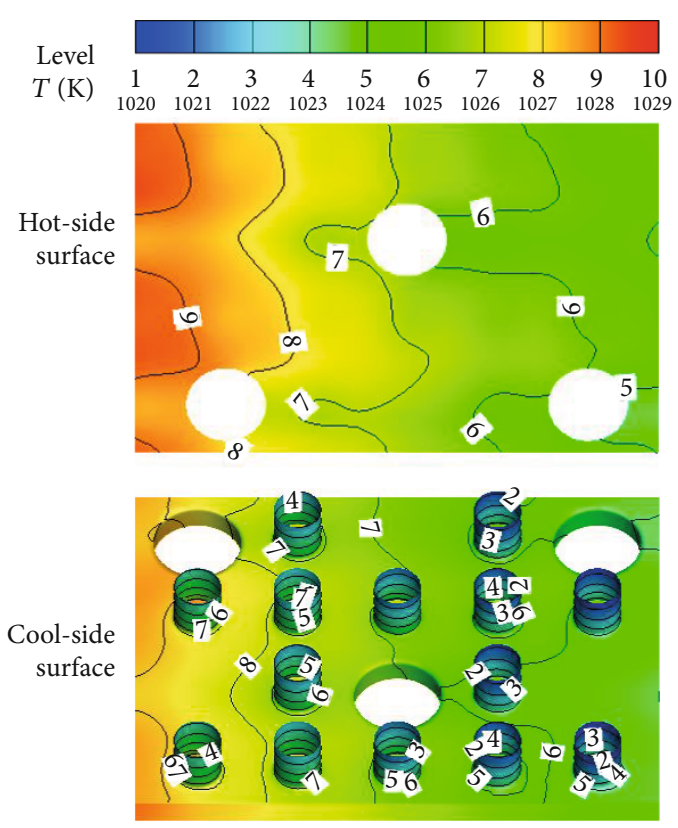

(a) $\mathrm{DR}=2.0$
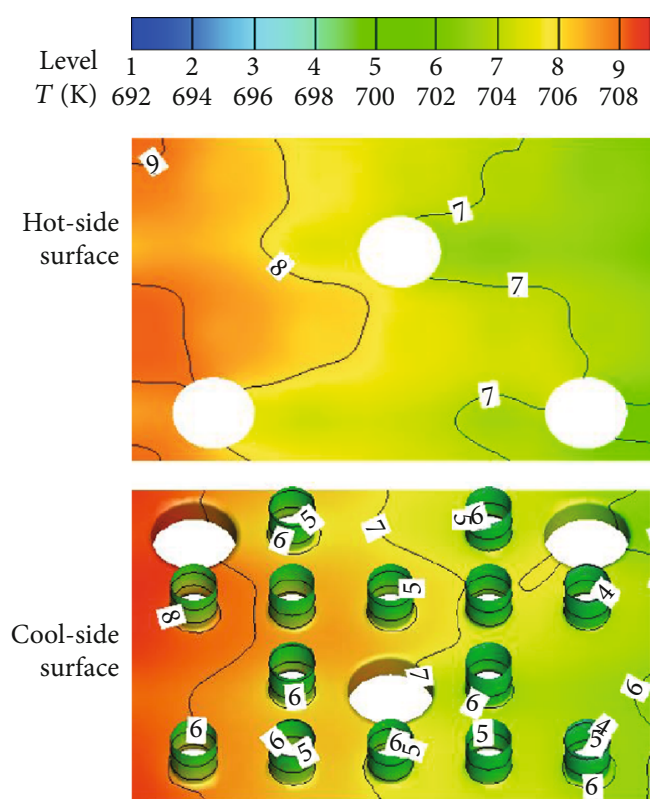

(b) $\mathrm{DR}=3.0$

FIGURE 12: Effect of density ratio on temperature distribution on film cooling plate.

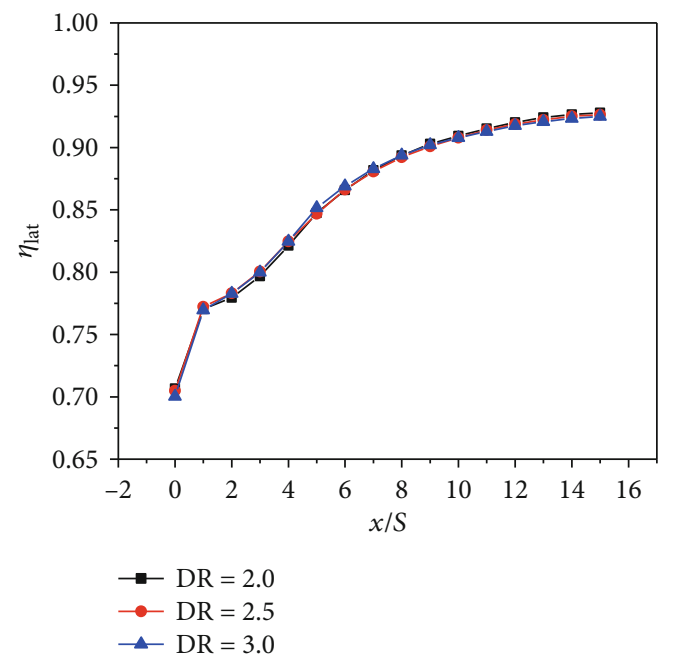

FIGURE 13: Influence of density ratio on cooling efficiency distribution.

is much weaker. For example, the area-averaged cooling efficiency changes $7.0 \%$ by increasing the film hole diameter from 0.9 to $1.5 \mathrm{~mm}$ but only $2.7 \%$ by increasing the impingement hole diameter from 0.9 to $1.5 \mathrm{~mm}$. It illustrates that film cooling takes the dominant role in laminated cooling.

Figure 19 shows the influences of pin fin diameter on temperature distribution. In the present cases, $\left(d_{\mathrm{i}}, d_{\mathrm{f}}, H\right.$, $S, P)=(0.9,1.5,1.0,6.8,6.8) \mathrm{mm}, G_{c}=8 \mathrm{~kg} / \mathrm{m}^{2} \mathrm{~s}$, and $\mathrm{DR}$ $=2.5$. As the pin fin diameter increases, the wall temperature decreases. The existence of the pin fin increases the heat exchange area and turbulent intensity inside the cavity, which enhances the convective heat transfer. Furthermore, pin fins connect the film plate and impingement plate and improve the heat conduction between two plates. For example, as the pin fin diameter increases from 0 to $0.8 \mathrm{~mm}$, the area-averaged temperature of the cool-side surface of the film plate decreases from $897 \mathrm{~K}$ to $850 \mathrm{~K}$, but the area-averaged temperature of the hot-side surface of the impingement plate increases from $825 \mathrm{~K}$ to $883 \mathrm{~K}$. Figure 20 shows influence of the pin fin diameter on cooling efficiency distribution. At $x / S=0$, the laterally averaged cooling effectiveness increases from 0.615 to 0.705 by increasing the pin fin diameter from 0 to $0.8 \mathrm{~mm}$. At $x / S=14.0$, the increase of the pin fin diameter causes the increase of the laterally averaged cooling effectiveness from 0.908 to 0.926 . Overall, increasing the pin fin diameter can improve the cooling performance.

Figure 21 shows the influence of the spanwise hole pitch and streamwise hole spacing on the hot-side wall temperature distribution. In the present cases, $\left(d_{\mathrm{i}}, d_{\mathrm{f}}, d_{2}, H\right)=(0.9$, $1.5,0.8,1.0) \mathrm{mm}, G_{\mathrm{c}}=8 \mathrm{~kg} / \mathrm{m}^{2} \mathrm{~s}$, and $\mathrm{DR}=2.5$. The increase of the hole pitch results in the decrease of the opening rate of the film hole, which deteriorates the coolant coverage. However, the impact of the hole spacing on the temperature distribution is contrary. Figure 22 shows the influence of hole arrangements on the cooling efficiency distribution. In the present cases, the cooling efficiency can be improved by increasing the hole spacing and decreasing the hole pitch. For example, the area-averaged cooling effectiveness decreases from 0.861 to 0.806 by increasing the hole pitch from $6.8 \mathrm{~mm}$ to $10.2 \mathrm{~mm}$ but increases to 0.875 by increasing the hole space from 6.8 to $10.2 \mathrm{~mm}$. 
$T(\mathrm{~K})$ $\begin{array}{lllllllllll}860 & 974 & 1088 & 1202 & 1316 & 1430 & 1544 & 1658 & 1772 & 1886 & 2000\end{array}$

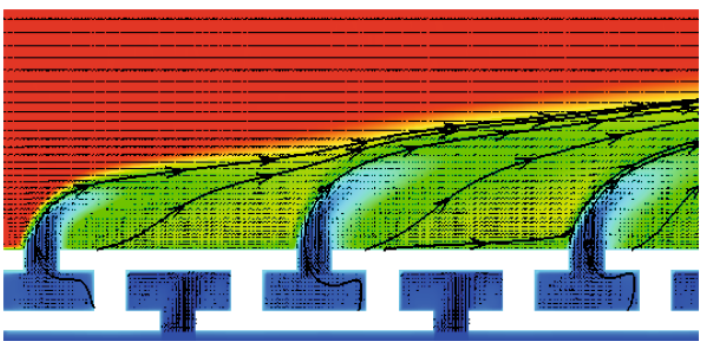

(a) $d_{\mathrm{f}}=0.9 \mathrm{~mm}$
$T(\mathrm{~K})$ $\begin{array}{lllllllllll}860 & 974 & 1088 & 1202 & 1316 & 1430 & 1544 & 1658 & 1772 & 1886 & 2000\end{array}$

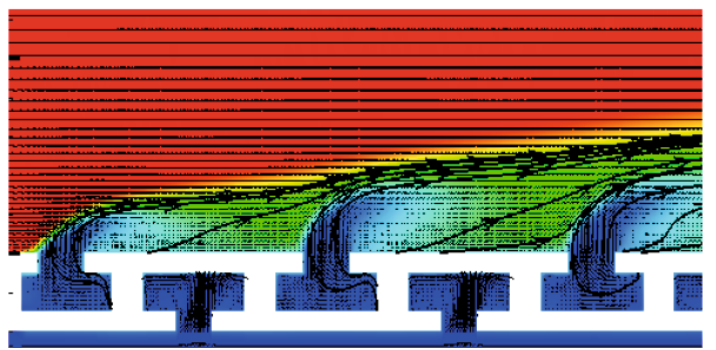

(b) $d_{\mathrm{f}}=1.2 \mathrm{~mm}$

FIGURE 14: Effect of film hole diameter on streamline distribution on central plane.

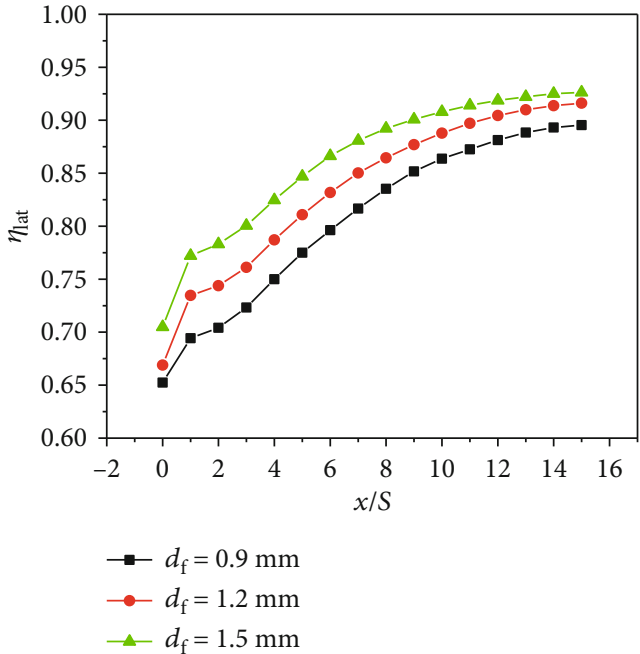

FIGURE 15: Influence of film hole diameter on cooling efficiency distribution.

4.3. Empirical Correlation. To ensure that the sampled design structures will be evenly distributed over the design space, the orthogonal test method was used, as displayed in Table 3, and 40 design structures are initially obtained. The method of the dynamic adjusting data to improve the forecast precision in the sample field is adopted, and a total of 48 design points were finally selected as training samples for the purpose of empirical correlation.

Based on the computational results (48 different structures $\times 6$ different working conditions), an empirical correlation is developed to predict the laterally averaged cooling effectiveness:

$$
\begin{aligned}
\eta_{\text {lat }}\left(\frac{x}{S}\right) & =\eta_{0}+n_{0}\left(\frac{d_{\mathrm{i}}}{d_{\mathrm{f}}}\right)^{n_{1}}\left(\frac{P}{d_{\mathrm{f}}}\right)^{n_{2}}\left(\frac{S}{P}\right)^{n_{3}}\left(\frac{H}{d_{\mathrm{i}}}\right)^{n_{4}} \varepsilon^{\mathrm{n}_{5}} \mathrm{DR}^{n_{6}}\left(\frac{G_{\mathrm{c}}}{\rho_{\infty} u_{\infty}}\right)^{n_{7}}\left(\frac{x}{S}\right)^{n_{8}}, \\
\eta_{0} & =n_{9}\left(\frac{d_{\mathrm{i}}}{d_{\mathrm{f}}}\right)^{n_{10}}\left(\frac{P}{d_{\mathrm{f}}}\right)^{n_{11}}\left(\frac{S}{P}\right)^{n_{12}}\left(\frac{H}{d_{\mathrm{i}}}\right)^{n_{13}} \varepsilon^{\mathrm{n}_{14}} \mathrm{DR}^{n_{15}}\left(\frac{G_{\mathrm{c}}}{\rho_{\infty} u_{\infty}}\right)^{n_{16}} .
\end{aligned}
$$

In the present study, the empirical coefficients $n_{0} \sim n_{16}$ were determined by the genetic algorithm (GA), and the optimization function is expressed by

$$
\begin{aligned}
& \text { fitness }=\text { mean }\left(\left|\eta_{\mathrm{cal}}-\eta_{\mathrm{CFD}}\right| \eta_{\mathrm{CFD}}\right), \\
& \text { s.t. }\left\{\begin{array}{l}
n_{0} \in[-1,1] \\
n_{1} \in[-1,1] \\
\ldots \\
n_{16} \in[-1,1]
\end{array}\right.
\end{aligned}
$$

where the subscripts "cal" and "CFD" denote the values determined by empirical correlation and the CFD model, respectively. The detailed introductions of GA are provided in Ref. [36, 37].

MATLAB software is used to perform GA optimization. In the optimization options, the population size is 240 (15 $\times$ number of variables), a tournament method with the size of 2.0 is used for the selection operation, a Gaussian function is used for the mutation function, an intermediate with the ratio of 1.0 is used for the crossover function, the migration process has a forward direction with the fraction of 0.2 , and the maximum iteration step is 200. Figure 23(a) shows the variation of best fitness value with the generation steps. It can be found that, as the iteration step reaches 70 , fitness values keep nearly stable (5.4\%). To test the generalization capability, cooling effectiveness calculated by empirical correlation is compared with the testing samples. As shown in Figure 23(b), the maximum relative error is $34.3 \%$, and the mean relative error is $8.3 \%$. The optimized values for $n_{0} \sim n_{16}$ are listed in Table 4 . Due to the numerous structural parameters of laminated configurations and complex influencing factors, the error of $8.3 \%$ can actually contain the requirements. However, compared with the film cooling, which has fewer parameters, the errors of four empirical correlations are less than 2\% [38]. Although the empirical formula error of laminated configurations does not reach this value, it can provide a reference for the subsequent research.

In order to verify the accuracy of the empirical formula, the Monte Carlo method and mean-square pure error 
$T(\mathrm{~K})$
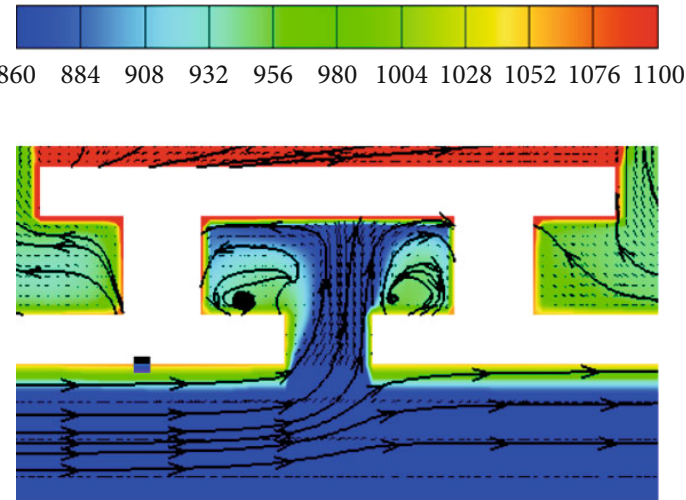

(a) $d_{\mathrm{i}}=0.9 \mathrm{~mm}, H=1 \mathrm{~mm}$
$T(\mathrm{~K})$
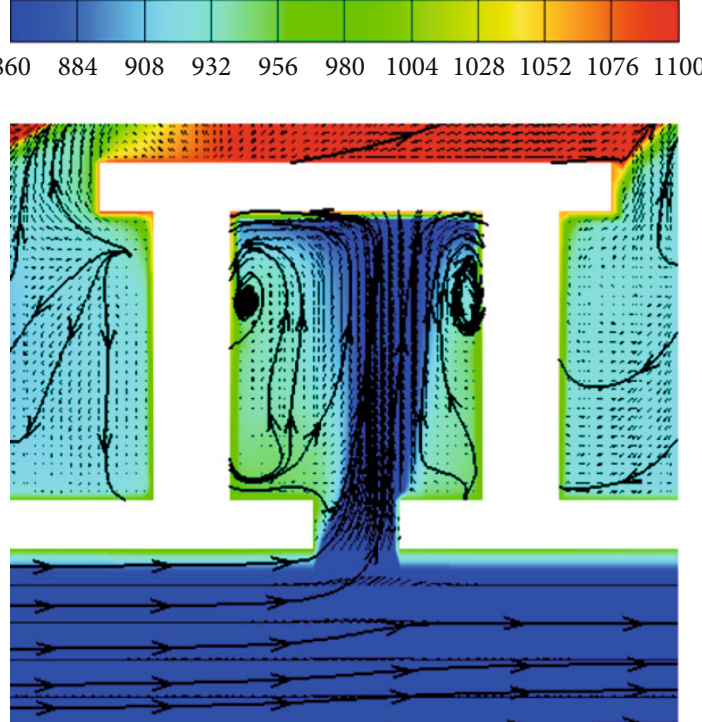

(b) $d_{\mathrm{i}}=0.9 \mathrm{~mm}, H=3 \mathrm{~mm}$

$T(\mathrm{~K})$ $\begin{array}{lllllllllll}860 & 884 & 908 & 932 & 956 & 980 & 1004 & 1028 & 1052 & 1076 & 1100\end{array}$

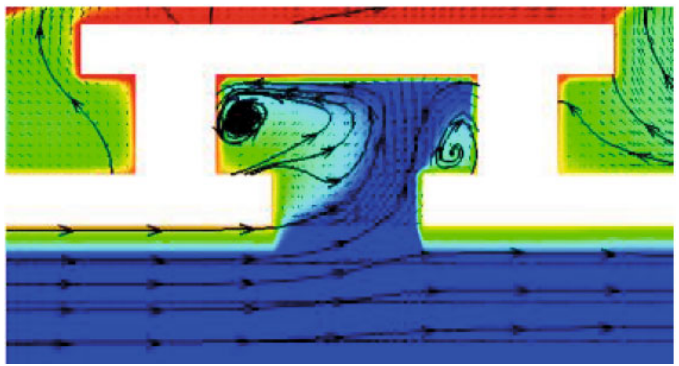

(c) $d_{\mathrm{i}}=1.5 \mathrm{~mm}, H=1 \mathrm{~mm}$

Figure 16: Effects of impingement hole diameter and height on streamline distribution on central plane.

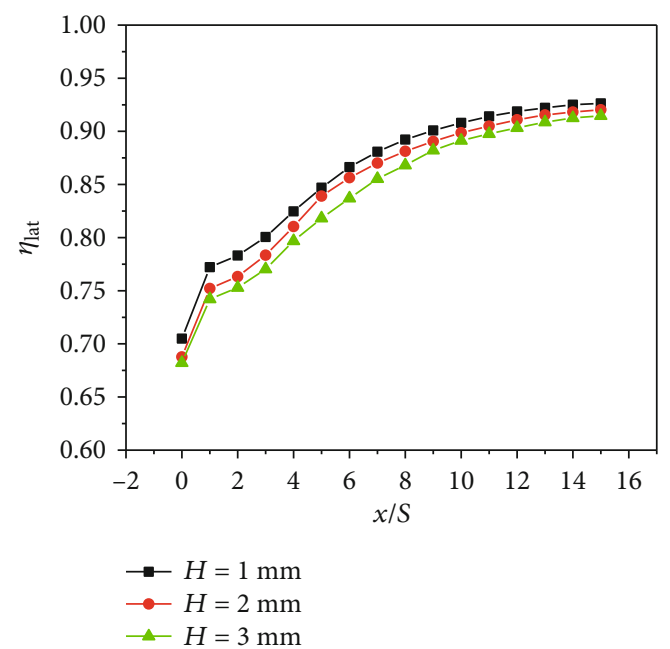

FIGURE 17: Influence of impingement height on cooling efficiency distribution.

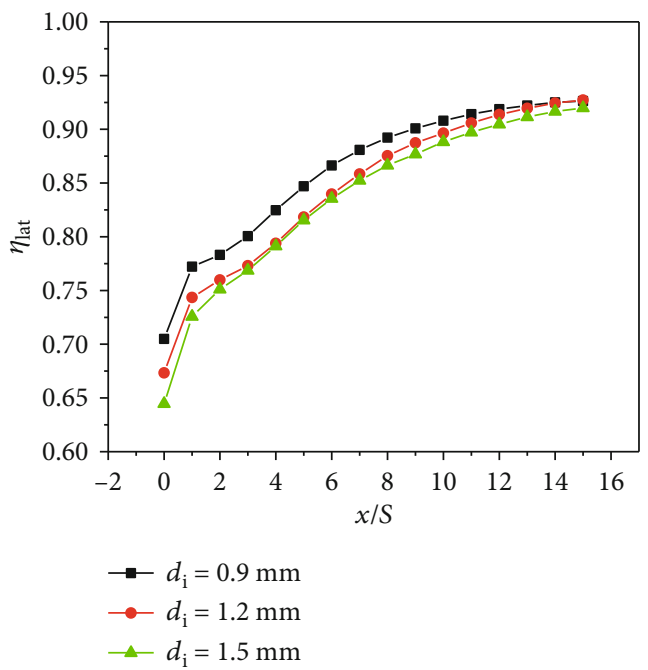

Figure 18: Influence of impingement hole diameter on cooling efficiency distribution. 


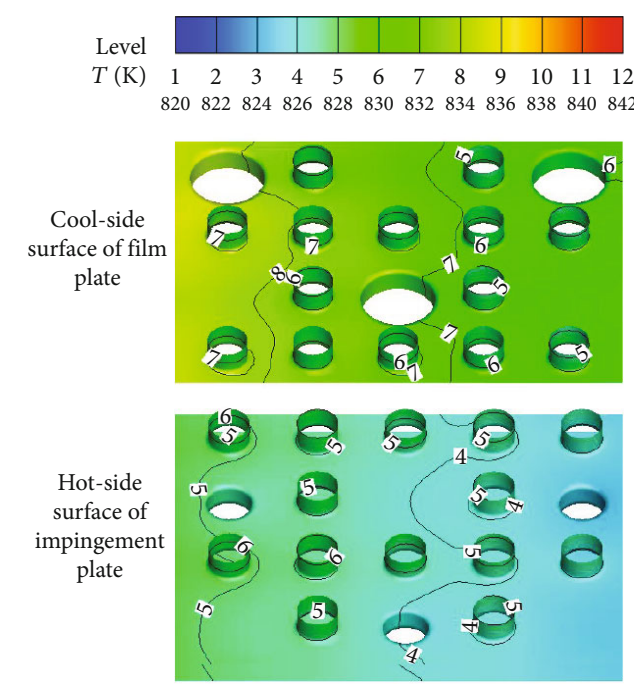

(a) $d_{2}=0.8 \mathrm{~mm}$
Level

$\begin{array}{lllllllllllll}T(\mathrm{~K}) & 1 & 2 & 3 & 4 & 5 & 6 & 7 & 8 & 9 & 10 & 11 & 12\end{array}$ $\begin{array}{llllllllllll}820 & 822 & 824 & 826 & 828 & 830 & 832 & 834 & 836 & 838 & 840 & 842\end{array}$
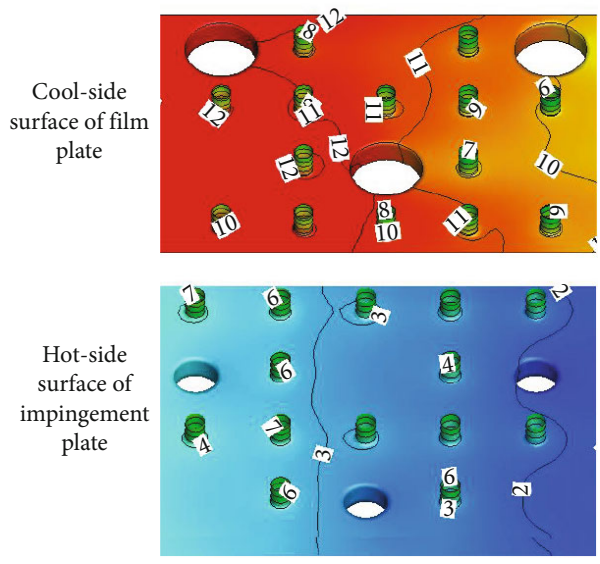

(b) $d_{2}=0.4 \mathrm{~mm}$

FIGURE 19: Effect of pin fin diameter on temperature distribution.

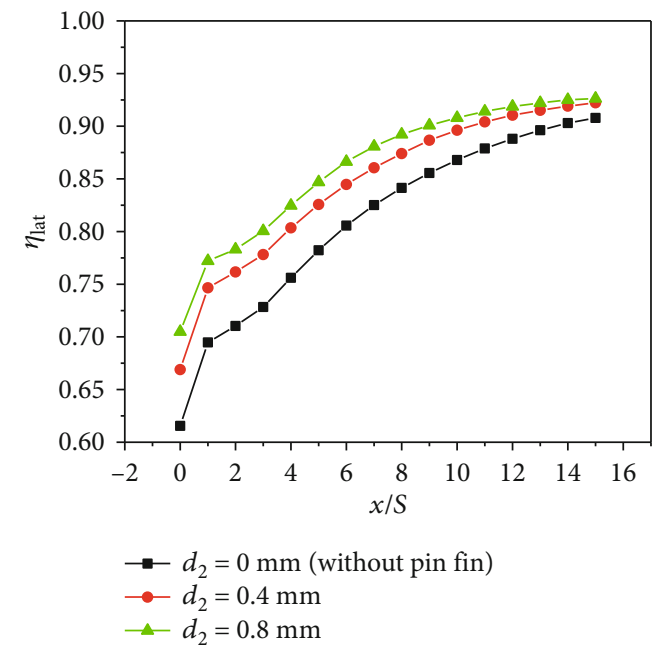

Figure 20: Influence of pin fin diameter on cooling efficiency distribution.
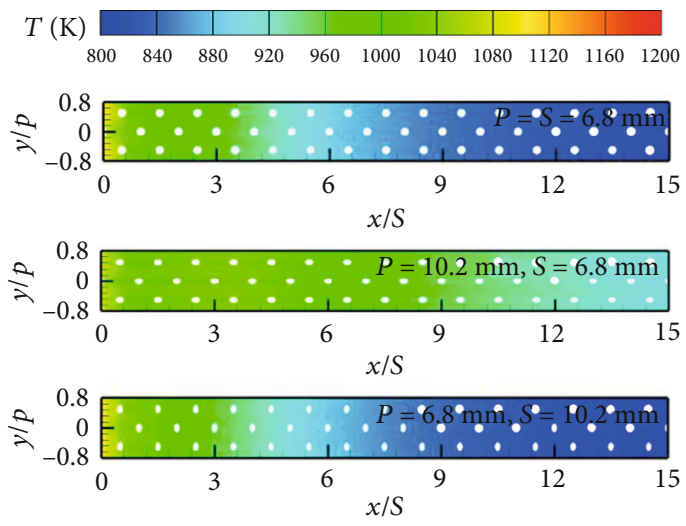

Figure 21: Temperature distribution on the hot-side surface at different hole arrangements.

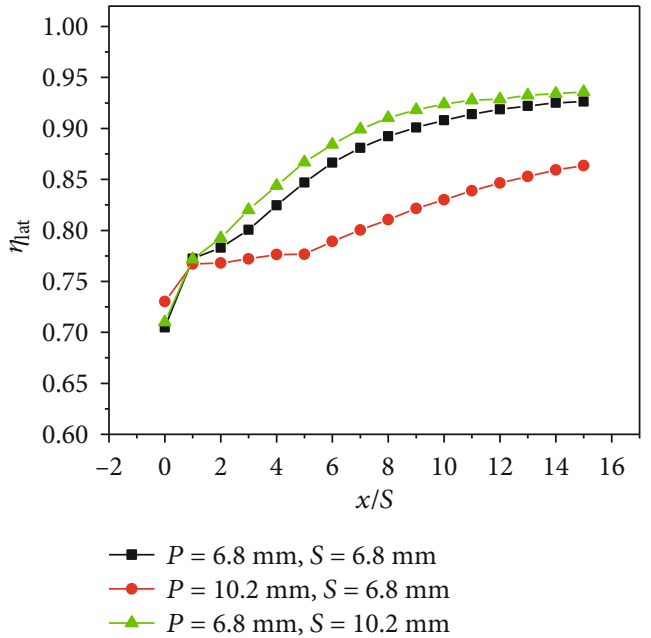

Figure 22: Influence of hole arrangement on cooling efficiency distribution.

TABLE 3: Orthogonal parameters.

\begin{tabular}{lccccc}
\hline Level & $d_{\mathrm{i}} / d_{\mathrm{f}}$ & $H / d_{\mathrm{i}}$ & $S / d_{\mathrm{i}}$ & $P / S$ & $\beta$ \\
\hline 1 & 0.5 & 0.5 & 6 & 1 & 0.35 \\
2 & 0.6 & 1.0 & 7 & 1.2 & 0.4 \\
3 & 0.7 & 1.5 & 8 & 1.4 & 0.45 \\
4 & 0.8 & 2.0 & 9 & 1.6 & 0.5 \\
5 & 0.9 & 2.5 & 10 & 1.8 & 0.55 \\
6 & 1.0 & 3.0 & 12 & 2 & 0.65 \\
\hline
\end{tabular}

(MSPE) analysis are proposed. The uncertainty analysis of the empirical parameters is used to determine the correctness of the empirical coefficients. Figure 24 shows the sensitivity results of empirical parameters. Among the empirical 


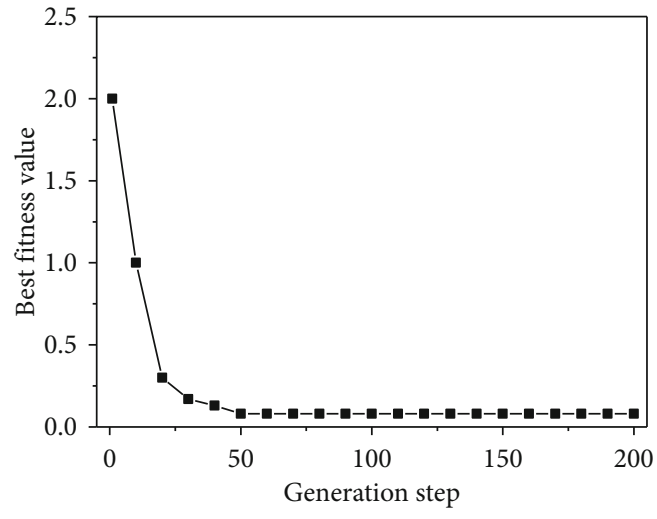

(a) Variation of fitness value with generation steps

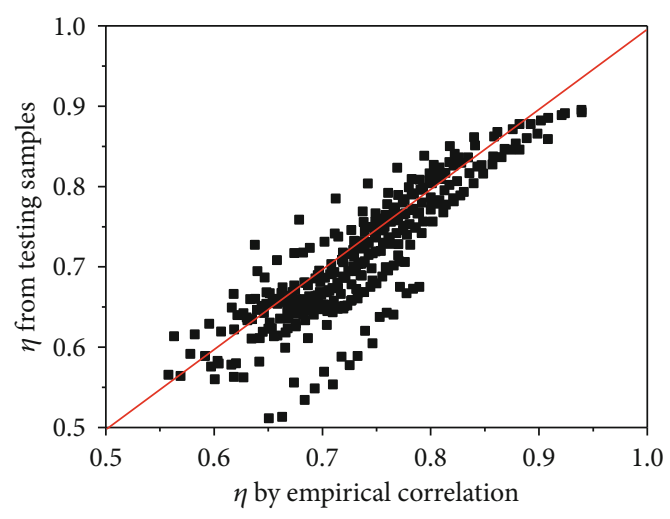

(b) Test of empirical correlation

FIGURE 23: GA optimization for the parameters in empirical correlation.

TABLE 4: Values for parameters in the empirical correlation.

\begin{tabular}{lccc}
\hline No. & Value & No. & Value \\
\hline$n_{0}$ & 0.451 & $n_{9}$ & 0.744 \\
$n_{1}$ & 0.321 & $n_{10}$ & -0.135 \\
$n_{2}$ & -0.502 & $n_{11}$ & 0.083 \\
$n_{3}$ & 0.576 & $n_{12}$ & -0.040 \\
$n_{4}$ & -0.082 & $n_{13}$ & 0.011 \\
$n_{5}$ & -0.518 & $n_{14}$ & 0.221 \\
$n_{6}$ & -0.423 & $n_{15}$ & -0.075 \\
$n_{7}$ & 0.422 & $n_{16}$ & 0.026 \\
$n_{8}$ & 0.491 & & \\
\hline
\end{tabular}

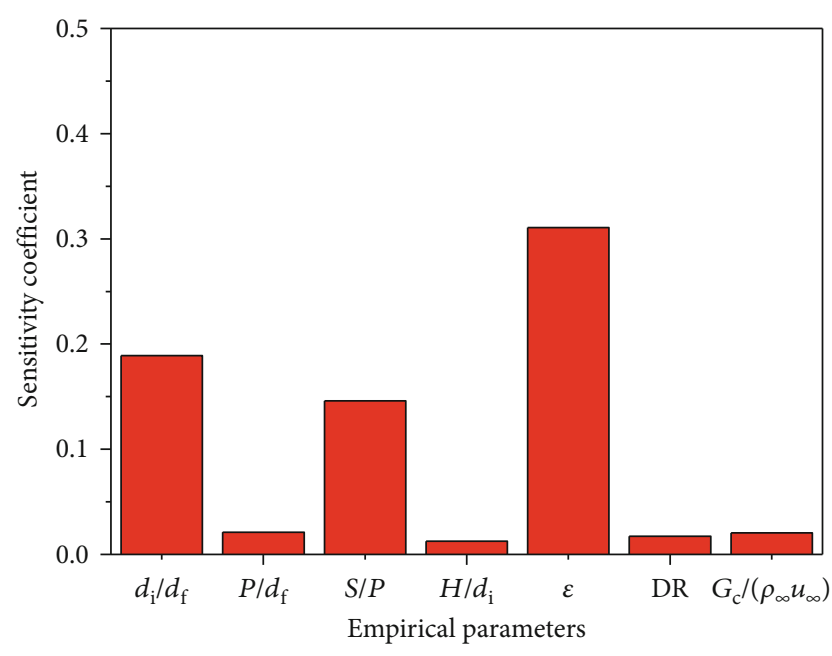

Figure 24: Sensitivity coefficient of empirical parameters. parameters, the structural parameters have the greatest effect on the overall cooling effectiveness, such as $\varepsilon$ and $d_{\mathrm{i}} / d_{\mathrm{f}}$, while the thermodynamic parameters have little effect on the effectiveness. By comparing the results of the uncertainty analysis with the empirical coefficients, obvious consistency can be found, which shows that the results of empirical formula are valuable.

\section{Conclusions}

In the present study, the influence of the geometric and thermodynamic parameters on the cooling performance of laminated configurations was studied in detail, and the calculation results were tested by model experiments. Based on the CFD calculation results, an empirical correlation was developed. Some useful conclusions were drawn from the study:

(1) At a low coolant flow rate, adding to the coolant flow rate results in the increase of the cooling efficiency. However, at a high coolant flow rate, the impact of the coolant flow rate on the cooling performance does not become obvious. In the present study, increasing the coolant-to-mainstream density ratio causes the decrease of the wall temperature, but has no obvious impact on the cooling efficiency

(2) At the same coolant consumption per unit area, increasing both the film cooling hole diameter and the pin fin diameter results in the increase of the cooling effectiveness, but the increase of the impingement hole diameter, impingement height, and hole spanwise pitch degrades the cooling performance

(3) A new correlation based on the genetic algorithm is developed for the prediction of the laterally averaged cooling efficiency of the laminated configuration

$$
\begin{aligned}
\eta_{\text {lat }}\left(\frac{x}{S}\right) & =\eta_{0}+0.451\left(\frac{d_{\mathrm{i}}}{d_{\mathrm{f}}}\right)^{0.321}\left(\frac{P}{d_{\mathrm{f}}}\right)^{-0.502}\left(\frac{S}{P}\right)^{0.576}\left(\frac{H}{d_{\mathrm{i}}}\right)^{-0.082} \varepsilon^{-0.518} \mathrm{DR}^{-0.423}\left(\frac{G_{\mathrm{c}}}{\rho_{\infty} u_{\infty}}\right)^{0.422}\left(\frac{x}{S}\right)^{0.491}, \\
\eta_{0} & =0.744\left(\frac{d_{\mathrm{i}}}{d_{\mathrm{f}}}\right)^{-0.135}\left(\frac{P}{d_{\mathrm{f}}}\right)^{0.083}\left(\frac{S}{P}\right)^{-0.040}\left(\frac{H}{d_{\mathrm{i}}}\right)^{0.011} \varepsilon^{0.221} \mathrm{DR}^{-0.075}\left(\frac{G_{\mathrm{c}}}{\rho_{\infty} u_{\infty}}\right)^{0.026} .
\end{aligned}
$$


The application range of the correlation is $G_{\mathrm{c}} \in[3,27]$ $\mathrm{kg} / \mathrm{m}^{2} \mathrm{~s}, \mathrm{DR} \in[2,3], d_{\mathrm{i}} / d_{\mathrm{f}} \in[0.5,1], H / d_{\mathrm{i}} \in[0.5,3], S / d_{\mathrm{i}} \in[6$, $12], P / S \in[1,2]$, and $\varepsilon \in[0.35,0.65]$.

\section{Nomenclature}

$d_{2}$ : $\quad$ Pin fin diameter $(\mathrm{mm})$

$d_{\mathrm{f}}: \quad$ Film cooling hole diameter $(\mathrm{mm})$

$d_{\mathrm{i}}: \quad$ Impingement hole diameter $(\mathrm{mm})$

DR: Coolant-to mainstream density ratio (-)

$G_{\mathrm{c}}$ : Coolant consumption per unit area $\left(\mathrm{kg} / \mathrm{m}^{2} \mathrm{~s}\right)$

$M: \quad$ Blowing ratio $\left(=\left(\rho_{\mathrm{c}} u_{\mathrm{c}}\right) /\left(\rho_{\infty} u_{\infty}\right)\right)$

$H$ : Impingement height $(\mathrm{mm})$

$P: \quad$ Spanwise hole pitch $(\mathrm{mm})$

$S: \quad$ Streamwise hole spacing $(\mathrm{mm})$

T: $\quad$ Temperature (K)

$u$ : $\quad$ Velocity $(\mathrm{m} / \mathrm{s})$

$x, y, z$ : Streamwise, spanwise, and vertical directions.

\section{Greek Symbols}

$\rho:$ Gas density $\left(\mathrm{kg} / \mathrm{m}^{3}\right)$

$\varepsilon$ : Blocking rate $\left(=4 d_{2} / P\right)$

$\eta$ : Cooling effectiveness $\left(=\left(T_{\infty}-T_{\mathrm{w}}\right) /\left(T_{\infty}-T_{\mathrm{c}}\right)\right)$.

Subscript

$\infty:$ Mainstream

c: Coolant

w: Wall

loc: Local value

lat: Laterally averaged value

cat: Centerline averaged value.

\section{Data Availability}

The data of tables and figures used to support the findings of this study are included within the article.

\section{Conflicts of Interest}

The authors declare that they have no conflicts of interest.

\section{References}

[1] T. F. Fric and A. Roshko, "Vortical structure in the wake of a transverse jet," Journal of Fluid Mechanics, vol. 279, pp. 147, 1994.

[2] A. Burdet, R. S. Abhari, and M. G. Rose, "Modeling of film cooling-part II: model for use in three-dimensional computational fluid dynamics," Journal of Turbomachinery, vol. 129, no. 2, pp. 221-231, 2007.

[3] C. Han, J. Ren, and H. D. Jiang, "Multi-parameter influence on combined-hole film cooling system," International Journal of Heat and Mass Transfer, vol. 55, no. 15-16, pp. 4232-4240, 2012.

[4] C. Han, Z. Chi, J. Ren, and H. Jiang, "Optimal arrangement of combined-hole for improving film cooling effectiveness," Journal of Thermal Science and Engineering Applications, vol. 7, no. 1, p. $011010,2015$.
[5] J.-s. Wei, H.-r. Zhu, C.-l. Liu, H. Song, C. Liu, and T. Meng, "Experimental study on the film cooling characteristics of the cylindrical holes embedded in sine-wave shaped trench," in ASME Paper GT2016-56856, vol. 5C: Heat Transfer, Seoul, South Korea, 2016.

[6] B.-l. Zhang, L. Zhang, H.-r. Zhu, J.-s. Wei, and Z.-y. Fu, "Numerical study on the influence of trench width on film cooling characteristics of double-wave trench," in ASME Paper GT2017-63552, vol. 5A: Heat Transfer, Charlotte, North Carolina, USA, 2017.

[7] C. F. Yang and J. Z. Zhang, "Experimental investigation on film cooling characteristics from a row of holes with ridgeshaped tabs," Experimental Thermal and Fluid Science, vol. 37, pp. 113-120, 2012.

[8] Y. Shan and J. Z. Zhang, "Numerical investigation on filmcooling characteristics from a rowof holes with ridge-shaped tabs," Journal of Enhanced Heat Transfer, vol. 20, no. 3, pp. 251-265, 2013.

[9] S. A. Hayes, A. C. Nix, C. M. Nestor, D. T. Billups, and S. M. Haught, "Experimental investigation of the influence of freestream turbulence on an anti-vortex film cooling hole," Experimental Thermal and Fluid Science, vol. 81, pp. 314326, 2017.

[10] T. W. Repko, A. C. Nix, C. Uysal, and J. D. Heidmann, "Numerical study on the effects of freestream turbulence on antivortex film cooling design at high blowing ratio," Journal of Thermal Science and Engineering Applications, vol. 9, no. 1, p. 011013, 2017.

[11] R. Bunker, "Turbine heat transfer and cooling: an overview," ASME paper No. GT2013-94174.

[12] G. E. Andrews, A. A. Asere, C. I. Hussain, M. C. Mkpadi, and A. Nazari, "Impingement/effusion cooling: overall wall heat transfer," ASME paper No. 88-GT-290.

[13] S. V. Ekkad, Y. Huang, and J. C. Han, "Impingement heat transfer on a target plate with film cooling holes," Journal of Thermophysics and Heat Transfer, vol. 13, no. 4, pp. 522528, 1999.

[14] P. Ligrani, A. Click, D. Ritchie, F. Liberatore, R. Patel, and Y. H. Ho, "Double wall cooling of an effusion plate with cross flow and impingement jet combination internal cooling: comparisons of main flow contraction ratio effects," International Journal of Heat and Mass Transfer, vol. 150, p. 119196, 2020.

[15] Y. Y. Liu, Y. Rao, and L. Yang, "Numerical simulations of a double-wall cooling with internal jet impingement and external hexagonal arrangement of film cooling holes," International Journal of Thermal Sciences, vol. 153, p. 106337, 2020.

[16] Rolls-Royce plc, The Jet Engine, United Kingdom, 1986.

[17] P. J. Ashmole, Introducing the Rolls-Royce Tay, Rolls-Royce Limited, 1983.

[18] A. B. Wassell and J. K. Bhangu, "The Development and application of improved combustor wall cooling techniques," ASME paper No. 80-GT-66.

[19] S. H. Kim, K. H. Ahn, E. Y. Jung, J. S. Park, K. Hwang, and H. H. Cho, "Total cooling effectiveness on laminated multilayer for impingement/effusion cooling system," ASME paper No. GT2014-26692.

[20] K. Funazaki and K. Hachiya, "Systematic numerical studies on heat transfer and aerodynamic characteristics of impingement cooling devices combined with pins," ASME paper No. GT2003-38256. 
[21] K. Funazaki, Y. Tarukawa, T. Kudo, S. Matsuno, R. Imai, and S. Yamawaki, "Heat transfer characteristics of an integrated cooling configuration for ultra-high temperature turbine blades: experimental and numerical investigations," ASME paper No. 2001-GT-148.

[22] C. Nakamata, F. Mimura, M. Matsushita, T. Yamane, Y. Fukuyama, and T. Yoshida, "Local cooling effectiveness distribution of an integrated impingement and pin fin cooling configuration," ASME Paper No. GT2007-27020.

[23] C. Nakamata, Y. Okita, S. Matsuno et al., "Spatial arrangement dependance of cooling performance of an integrated impingement and pin fin cooling configuration," ASME Paper No. GT2005-68348.

[24] L. Luo, C. Wang, L. Wang, B. Sunden, and S. Wang, "Computational investigation of dimple effects on heat transfer and friction factor in a Lamilloy cooling structure," Journal of Enhanced Heat Transfer, vol. 22, no. 2, pp. 147-175, 2015.

[25] L. Luo, C. Wang, L. Wang, B. Sunden, and S. Wang, "Effects of pin fin configurations on heat transfer and friction factor in an improved Lamilloy cooling structure," Heat Transfer Research, vol. 48, no. 7, pp. 657-679, 2017.

[26] J. H. Wang, X. J. Lv, Q. D. Liu, and X. Y. Wu, “An experimental investigation on cooling performance of a laminated configuration using infrared thermal image technique," ASME paper No. GT2009-59838.

[27] J. Pu, W. Wang, J. H. Wang, W. L. Wu, and M. Wang, "Experimental study of free-stream turbulence intensity effect on overall cooling performances and solid thermal deformations of vane laminated end-walls with various internal pin-fin configurations," Applied Thermal Engineering, vol. 173, p. 115232, 2020.

[28] Y. Rao, Y. Liu, and C. Wan, "Multiple-jet impingement heat transfer in double-wall cooling structures with pin fins and effusion holes," International Journal of Thermal Sciences, vol. 133, pp. 106-119, 2018.

[29] P. C. Sweeney and J. F. Rhodes, "An infrared technique for evaluating turbine airfoil cooling designs," ASME Journal of Turbomachinery, vol. 122, pp. 170-177, 2020.

[30] X. M. Tan, J. Z. Zhang, and Q. Z. Cai, "Effects of pin-fin shapes on mesh-fed slot film cooling for a flat-plate model," Journal of Thermal Science and Engineering Applications, vol. 11, no. 3, p. 031002, 2019.

[31] C. Wang, J. Z. Zhang, C. H. Wang, J. Ji, and X. M. Tan, “Geometric-parameter influences on and orthogonal evaluation of thermomechanical performances of a laminated cooling structure," Heat Transfer Research, vol. 51, no. 1, pp. 57-82, 2020.

[32] W. L. Zhou, Q. H. Deng, W. He, and Z. P. Feng, "Effects of hole pitch to diameter ratio $\mathrm{P} / \mathrm{D}$ of impingement and film hole on laminated cooling effectiveness," ASME paper No. GT201764566.

[33] ANSYS Fluent 14.0 User's Guide, ANSYS Inc., Canonsburg, 2012.

[34] GAMBIT 2.2 Tutorial Guide, ANSYS Inc., Canonsburg, 2004.

[35] J. Ji, A Study on Overall Cooling Effectiveness in a ImpingementPin-Film Lamilloy Cooling Configuration, [PhD thesis], Nanjing University of Aeronautics and Astronautics, 2019.

[36] C. H. Wang, J. Zhang, and J. Zhou, "Optimization of a fanshaped hole to improve film cooling performance by RBF neural network and genetic algorithm," Aerospace Science and Technology, vol. 58, pp. 18-25, 2016.
[37] A. J. Chipperfield and P. J. Fleming, The Matlab Genetic Algorithm Toolbox, IEE Colloquium on Applied Control Techniques Using MATLAB, London, UK, 1995.

[38] R. S. Bunker, Gas Turbine Handbook, Department of Energy, US, 2005. 